- This paper discusses the possible integration of counselling into general dental practice.

- The reasons behind the public perception of dentistry need to be understood as they relate to fear and anxiety in the surgery: historical, pain related, developmental and childhood experiences, and in the older generations.

- Patient-dentist relationships focussing on the interpersonal relationship in the surgery are described together with case scenarios demonstrating where counselling might have assisted the patient.

- The appropriate use of counselling skills v face-to-face counselling is outlined.

- It is recommended that a counsellor be integrated into the dental team as advisor, educator and for direct referrals.

\title{
How relevant is counselling in relation to dentistry?
}

\author{
G. Hoad-Reddick'
}

\begin{abstract}
This article attempts to explain reasons behind the general public's fear of dentistry by examining the historical perspective and, using case scenarios, demonstrates areas where patients' dental treatment might have been helped by the use of counselling. Distinguishing between the use of counselling skills vis-áa-vis professional counselling, the wider issues for the dental profession - education, boundaries and the need for referrals - are explored. It is suggested that if a counsellor were included as part of the dental team, patients and professionals would benefit. The counsellor could act as an advisor and educator for the team in addition to undertaking professional counselling on referral. Patients with anxiety or phobias could be recognised and helped appropriately and occupational stress experienced by practitioners would be reduced.
\end{abstract}

\section{INTRODUCTION}

Dental journals have long contained articles relating to the stress experienced by dentists $^{1-4}$ and recently there has been a focus on the stress experienced by dental students. ${ }^{5-7}$ But, what about the patients?

This paper aims to consider ways in which the use of trained counsellors as part of the dental team could enhance the experience for the patient, allow better treatment by the team and distinguish between the patient who is genuinely nervous and one who has a dental phobia which may be a symptom of a deeper psychological disturbance.

The unpleasantness of dentistry seems to be generally accepted ${ }^{8}$ and may date back to the barber surgeons of the seventeenth and eighteenth centuries when teeth were extracted without anaesthesia and the rich had teeth implanted into their empty sockets from the poor. ${ }^{9}$ Indeed this was one of the fates experienced in Victor Hugo's

1*Senior Lecturer in Dental Education, University Dental Hospital of Manchester, Higher Cambridge Street, Manchester M15 6FH

*Correspondence to: Gillian Hoad-Reddick

Email: Gill@reddick30.fsnet.co.uk

Refereed Paper

doi:10.1038/sj.bdj.4811410

Received 31.01.03; Accepted 14.10.03

๑ British Dental Journal 2004; 197: 9-14 original version of 'Les Miserables'; ${ }^{10}$ as well as selling her hair and her virtue, the heroine also sold her teeth. When teeth were extracted without anaesthetic a drum was banged to drown the patient's screams. ${ }^{11}$ Until the middle of the twentieth century it was common, in the North of England, for young women to have their teeth extracted and dentures fitted before marriage $;{ }^{12}$ this pattern is still reflected in the varying levels of edentulousness in different parts of the UK. ${ }^{13,14}$ Since for generations dentistry has had unpleasant connotations perhaps it is not surprising that the stigma remains and still many people fear a visit to the dentist.

It could be argued that this perception is because dentistry is so painful. But, the anaesthetic use of nitrous oxide was developed in 1844 by Horace Wells a dental surgeon of Hartford, Connecticut, USA, to alleviate pain experienced during removal of a third molar ${ }^{15}$ and, with the development of local anaesthesia, pain experience should be minimal if not non-existent. Yet still many people dread a visit to the dentist even if, as in the less caries prone younger generation, they have not experienced dental treatment.

The psychological importance of the oral cavity relates back to embryological development; the oral tissues develop by week 7 in utero and often the foetus can be seen on ultrasound sucking his/her thumb. ${ }^{16}$ After birth, suckling and maternal bonding are recognised as important by psychologists. ${ }^{17}$ The mouth assumes importance in relationships through the range of facial expressions exhibited by the muscles of facial expression, mouth and lips - smiling, anger, shyness etc. ${ }^{18}$ Non-verbal activity provides up to $65 \%$ of the information in human communication, ${ }^{19}$ much through facial expression. In the most intimate relationships, kissing and use of the oral cavity play a crucial role. Since dentistry is performed in a highly sensual area of the body perhaps it is not surprising that patients feel vulnerable during treatment and may suffer from dental anxiety - fear of the treatment per se - or from dental phobias where the problem may relate to deeper psychological problems.

Childhood experiences are important. If parents do not provide a good diet or encourage tooth-cleansing, the first experience of dentistry may be of extractions under general anaesthesia (GA). Where parents are apprehensive, this may cause the child, sensing the parents' stress, to become frightened in turn. The use of phrases like: 'I'm not going to hurt you' or, 'the dentist isn't going to hurt you' do not reassure but implant the idea of pain in addition to fear. Once an individual has 
had a negative experience, the likelihood of their readily seeking dental treatment in the future is slim. A nervous child is unable to differentiate between pain caused by the illness and that caused by a doctor or dentist while performing a clinical task; some of this pain may be real and some psychological due to fear. ${ }^{20}$ If first experiences can occur in an informal and relaxed setting the individual is more likely to accept future dental treatment and possibly might enjoy it.

In the school and teen years children are dependent on their parents and may not receive regular check-ups if the parents are afraid. It is therefore important that nursing mothers are educated so that children have the best 'dental' start in life. As preadolescent children start to become independent, the problems of overseeing their oral hygiene - encouraging good toothbrushing habits and a responsible attitude to sugar-consumption - may cause stresses to affect the relationship between parent and child.

Good dental care is important to the individual for two reasons: pain and selfperception. Dental pain is particularly unpleasant since the area has such a rich nerve supply and also, because it is situated close to the brain, the pain is particularly offensive. The self-perception aspect is especially pertinent in today's society where appearance is so important. In earlier times many peoples' teeth were decayed and ugly; it is suggested that the enigmatic smile of the Mona Lisa is as it is, because she could not display her decayed teeth. As adolescents mature interest in their appearance may make them focus on their teeth.

Middle-aged women may report that during pregnancy their teeth started to decay. Possibly during pregnancy women neglect tooth cleansing and are unaware of dental problems until they have time to themselves when the children are older or until tooth-ache drives them to act. They may start to question whether their appearance has declined and attend for treatment hoping their looks can be restored.

Elderly people often attend the surgery after years of neglect and non-attendance when their terminal dentition is becoming painful and eating difficult. ${ }^{21}$ For generations people have accepted they will lose the majority of their teeth as they age. Indeed, in 'As you like it', Shakespeare ${ }^{22}$ describing the last stage in his 'strange eventful history' of the seven ages of man, recognised the symbolism of tooth loss:

........Last scene of all,

That ends this strange eventful history, Is second childishness, and mere oblivion' Sans teeth, sans eyes, sans taste, sans everything'

\section{THE DENTIST-PATIENT RELATIONSHIP}

The dentist-patient relationship is unique in the medical area. The general dental practitioner (GDP) both diagnoses the problem and undertakes the treatment, which differs from general medicine where the practitioner sees the patient and may prescribe drugs or tests, but usually refers the patient on for specialist or hospital treatment.

Clearly, dentists deal with people who have a wide range of past experiences affecting their willingness or ability to accept treatment. On first meeting a patient the dentist has to investigate the patient's history focussing on pain or a specific problem; ${ }^{23}$ the dentist considered by the patient to be merely a 'technician', may react as one, performing requested procedures. Sadly, this may lead to over-treatment as the dentist, realising the patient expects treatment, removes a filling or eases a denture when in fact the problem may be caused by localised trauma which would heal itself in a few days. A patient with an underlying psychological problem may present with clinical symptoms (Clinical Case Study 1); a clinician not trained or able to recognise life problems may treat the presenting problem mechanistically with the consequence that the condition fails to improve or becomes chronic. ${ }^{24}$ This produces further distress for the patient, further consultations and prescriptions and also additional cost for the healthcare provider.

It is important that when patients display visible psychological distress, they are approached with caution and given the opportunity to explore whether the underlying problem is dental anxiety or a dental phobia, symptomatic of a psychological disturbance. ${ }^{25}$ When dealing with a nervous patient, much of the appointment should be used to calm them, explaining the processes involved and, giving them time, allowing them to present their oral symptoms and concerns about themselves. A good chair-side manner and excellent team approach makes the appointment less frightening for these individuals. ${ }^{23}$ Moulton $^{17}$ suggests 'good therapy starts with good history-taking' establishing the basis for good communication and confidence building. Where patients are obviously distressed it provides the opportunity for the dentist to attempt to determine whether the distress is due to dental anxiety or other more deep-seated psychological causes; ${ }^{26}$ the pain may be a somatic representation of a psychical pain'. ${ }^{27}$

There are cases where it is apparent that other aspects of the patient's life affect their need for, or ability to, accept treatment (Clinical Case Study 2). The agenda may differ from the apparently presenting one; the dentist should try to be aware of the existence of both overt and covert agendas ${ }^{27}$ as, without this understanding, treatment will be compromised. The patient may divulge sensitive and affecting material (Clinical Case Study 3). Often people are lonely and unhappy and to be presented with a caring, listening person willing to give them time, enables them to share problems they are unable to discuss elsewhere.

Three different emotionally related mechanisms can produce pain: emotional tension, anxiety and hysteria. ${ }^{28}$ Patients with psychological or emotional problems may 'take it out on their teeth', grinding excessively, especially at night. ${ }^{29-31}$ Not only may this wear the teeth down, it may also affect the muscles of mastication and the temporo-mandibular joint (TMJ) (Clinical Case Study 1).

Certain areas of dentistry have long been recognised as suitable for help by psychotherapy or hypnosis; particularly treatment of retching patients, ${ }^{32,33}$ and dental phobics where patients may exhib-

\section{Case study 1}

A young woman had attended dental casualty complaining of pain, lasting for 3 months, in her left temporo-mandibular joint region causing headaches and affecting her ability to sleep. Radiographs showed no abnormality but it was assumed that joint problems were the cause. Treatment included manipulation of the joint under GA, electro-physiotherapy and provision of a splint designed to separate her teeth and prevent bruxism

One year later the patient attended a dentist who was trained as a counsellor. The patient had a severe lack of confidence, spoke quietly and could not make decisions or assume responsibility for her own actions always blaming others; she was upset and said problems with her partner were making her ill, causing her to grind her teeth more than usual and damage her joint again. Using counselling skills (and a cognitive behavioural approach) to help her develop coping strategies, she was shown how to accept responsibility for her own actions and was helped to understand that she was allowing her life-problems to affect her joint. Over several meetings she gained in confidence; also, her joint stopped hurting.

In this case, using the cognitive behavioural therapy (CBT) model (Rosser 1994), it was explained to the patient that unconscious thoughts could have affected her behaviour, moods and her physical and physiological make-up. By allowing her to recognise patterns of distorted thinking and dysfunctional behaviour she was helped to improve her self-esteem and become responsible for her own actions; it seems that a long-standing clinical problem was resolved. 
Case study 2

The patient, an 80-year-old woman, was brought to the surgery by her daughter, P. She was taking warfarin as she had received a heart valve replacement. P. had taken a day off work to bring her mother for treatment and resented the time involved especially as she has 3 children to care for as well as an employer who resents her taking time off work. The dental treatment involved in providing a temporary reline and later replacing the patient's denture was originally scheduled to take at least 8 appointments. When this was explained to $P$, she broke down in rage and frustration as she felt her life had been taken over by her mother and no-one was listening to her. Her anger at having to balance her own life with the care of her mother spilt over.

It was evident that in order to help the patient we also had to relate to her daughter. So, using counselling skills and listening to P's story, the treatment was arranged with fewer hospital visits. The social arrangements of the family and not just the 'dentally correct procedures' for the patient concerned were taken into consideration. If the family situation had not been resolved, resentment could have built up between $\mathrm{P}$. and her mother so necessary treatment might not have been completed and $\mathrm{P}$ might have taken it out on her children or at worst lost her job.

\section{Case study 3}

The 40-year-old, female patient attended for the provision of complete dentures. During history taking the patient became tearful. She was childless, had been married for 10 years and was overcome to be able to speak to someone in confidence. Wearing dentures made her feel vulnerable and increased her awareness of her poor relationship with her husband who ridiculed her 'toothless state'. Until this opportunity she had not been able to share her distress with anyone. Further empathic conversation elicited the information that her husband was unable to maintain an erection, his penis being flaccid at all times.

Clearly this patient required further help. It was suggested that she contact her doctor in confidence. Several weeks later she announced that she had spoken to her doctor, and also had found the courage to speak to her husband; together they were seeking help.

Why was this patient able to speak in a dental clinic when she had not spoken about this problem previously? Clearly, the patient's agenda was more complex than the presenting agenda. The close and intimate relationship allowed her to feel that someone was giving her time and listening.

it unexplained physical symptoms or focus excessively on their dental problems (dysmorphophobia) ${ }^{29}$ indicative of a psychological distubance. ${ }^{34,35}$ If these patients are given time, with careful explanation of each stage of treatment, allowing it to take place on their terms rather than following the dentist's agenda, many of them can successfully be treated by a dentist using the core counselling skills described by Rogers - empathy, congruence and unconditional positive regard - (attentive listening, an ability to understand the other person's viewpoint as if from their own perspective and an ability to summarise the feelings of the other person so they can emotionally engage with their viewpoint) ${ }^{36}$ (Clinical Case Study 4).

There are however other areas where psychotherapy or professional counselling rather than simply the use of counselling skills would be effective. Cancer patients suffer great stress during and after treatment. In some areas of cancer therapy, for example mastectomy, psychological support is generally available for patients. Major maxillo-facial reconstruction and cancer operations on the head and neck, face and in the mouth, are particularly stressful as a person's sense of themselves is totally identified with their facial appearance. Changes to this area have ramifications extending beyond the immediate physical facts, ${ }^{17}$ yet counselling is not routinely available. Clinical results following operations to the head and neck, relating to appearance or scarring may be upsetting to a patient and prostheses to replace an eye or nose often fall short of convincing. It could be argued that these patients are 'lucky' to be alive but what about the quality of life? (Clinical Case Study 5).

If a psychologist or counsellor were always included in surgical teams, patients and their families would be able to approach the operation supported, with greater understanding and less fear. When the dentist-patient relationship is successful, patients develop faith in their clinician trusting them to work in the very sensitive area, constantly invading their personal space. Obviously a surgeon cannot always be sure of surgical outcomes but often patients are afraid to ask or are so overcome by emotion or fear, they cannot think of the right questions. In his book 'Cowards get cancer too....' John Diamond ${ }^{38}$ charted the progress of his own disease demonstrating the need for support to ease misery and suffering.

Success or failure rates of operations may have been mentioned by the surgeon: John Diamond had been warned he might not be able to swallow but the reality of saliva dribbling constantly from his lower lip made his plight much worse. He did not seem to resent the lack of 'proper' informa- tion and had a supportive family but for many patients, the loneliness of their suffering is severe.

'And as so many of my correspondents were keen to remind me, however sympathetically, hardly any of my squeezing and sluicing or the symptoms which occasioned them had anything to do with cancer. They were the products of the cure for cancer ('cure' being the word which all too often they put in quotation marks so as to show how hollow they thought the concept to be). This was iatrogenic illness: illness caused by doctors.

They were right. Iatrogenic illness was just what it was. And there were times when I had to remind myself that it was the iatrogenic illness which was saving my life. 38

Many doctors' GP surgeries now employ counsellors for those who are anxious or depressed, for nervous patients with mild psychiatric conditions and also for a wide range of people not suffering from a specific complaint, but not coping satisfactorily with their lives. It would seem from the above case scenarios that there would be a place for referral of such patients by dental surgeons as well as by doctors.

\section{THE DENTIST AND COUNSELLING SKILLS VERSUS COUNSELLING}

\section{Counselling skills}

It was not until 1997 that a General Dental Council directive specifically included behavioural sciences in the undergraduate curriculum. ${ }^{39}$ Thus most dentists practising today have had little direct teaching about counselling skills but will, if lucky, have 'picked them up' from their teachers. There can be no doubt that good dentists use the core concepts of counselling with their patients, ${ }^{36}$ either during history taking, or while explaining treatment options or practicalities and will be able to recognise psychosomatic symptoms and react accordingly. General dental practitioners describe their main reason for leaving the health service to work in private practice as wanting to be able to spend more time with their patients, ${ }^{40}$ indicating a wish to enjoy a closer working relationship with patients. It could be argued that patients will respond with their feet and, where a dentist does not show sufficient empathy, congruence and unconditional positive regard, they will not return or recommend the dentist to other prospective patients.

However, it is very important that, in the close relationship with the patient, the dentist is aware of the dangers involved in allowing them to open up and discuss long-term unresolved problems. McLeod ${ }^{41}$ cautions: 


\section{Case study 4}

The patient was a woman in her mid-thirties with four children aged between 3 and 12 years which she was bringing up on her own. She had not been to a dentist for 10 years and, as time had gone on, had realised her teeth were getting worse. The longer she delayed treatment, the greater the fear; she was aware that some of her front teeth were not only painful but also so loose they were about to fall out. She attended her local GDP who referred the patient to a consultant in restorative dentistry.

During the meeting with the consultant an oral examination was not possible as the patient was too scared to co-operate with anything he asked her to do. This consultant always has a very full clinic so is not able to spend time if patients are not compliant. He prefers to undertake 'aesthetic dentistry', providing crowns, bridges and implants which require considerable technical skill. He therefore referred the patient on to a dentist who routinely uses counselling skills when treating patients.

Using counselling skills and non-threatening body language, the dentist spent three-quarters of an hour with the patient at their first meeting. Sitting lower than the patient, and discussing her feelings and fears about dental treatment, explaining what treatment would involve and what would happen if she continued to delay treatment, her confidence was gained. She allowed the dentist to examine her mouth, first visually, later with a mouth-mirror and finally - still at the first appointment - primary impressions were taken after careful explanation of the possibility of the loose teeth remaining in the impression.

\section{Case study 5}

A young man was 16 when pain and an unpleasant discharge first affected his maxillary sinus. After three months, cancer affecting the anterior wall of the antrum was diagnosed. An operation ensued leaving him with residual scarring of his cheek. Although provided with an obturator, to keep the space patent, he found it uncomfortable so kept refusing to wear it. As a result scarring occurred; aged 20, he asked for an operation to improve his appearance.

At no time had this patient been offered counselling to help him overcome his fear of the disease and its aftermath. It is suggested that had he been provided with support from a psychologist or counsellor attached to the surgical team, during planning stages of treatment as well as afterwards, the final result would have been more successful and he would have found the ordeal less frightening and less traumatic. Also, the long-term result would have been better. 'where untrained people attempt to undertake counselling the clients may become confused, or damaged when people attempting to help them get enmeshed in role conflicts through attempting to counsel as well as be their teacher'.

Should the patient disclose material indicating the need for further exploration by a counsellor or other medical personnel, the dentist should refer the patient on. Otherwise the patient may have to deal with emotional issues they are not ready or able to deal with at that time. In order to be able to facilitate this referral effectively, it would be wise for a dentist to have a liaison with a suitable counsellor willing to accept referrals. The counsellor, who could be considered part of the dental team, could also educate them to ensure boundaries are understood and respected .

\section{Counselling}

Counselling involves strict boundaries of task, role, time and confidentiality with counsellors having supervision to ensure clarity, awareness of issues and judiciousness of response (for example transference and counter-transference) affecting their own ability to attune effectively to a client or manage a particular case. ${ }^{42}$ The counsellor's skill lies in knowing when to respond with emotional engagement, when to focus on understanding and perspective and when to join in a collaborative relationship. ${ }^{43}$ They are also trained to recognise severe psychological disturbance or psychotic states and refer the patient on where appropriate.

\section{Appropriate type of counselling}

If a counsellor were attached to a dental practice as part of the team $\mathrm{s} /$ he could have two roles to:

- Advise and educate the team on 'best practice'. The team members could be made aware of the roles they take up in relationships with patients.
- Help patients who could benefit from counselling - a direct referral pathway.

A counsellor in this role would need to be flexible. An integrated approach allowing both of the above roles to be adopted might include:

- Education of the team on the use of counselling skills

- Person-centred counselling

- The Egan model

- Psychodynamic counselling

- Cognitive behavioural therapy

Education on the use of counselling skills As a member of the dental team, the counsellor could ensure that all members used adequate counselling skills. Rogers' three core elements (empathy, congruence and unconditional positive regard) ${ }^{36}$ and the need for awareness of boundaries and onward referral would be stressed. If a dentist is aware of a good onward referral pathway, s/he is more likely to use it.

\section{Person-centred counselling}

Clinical Case 3 demonstrates the dentist using a person-centred approach using counselling skills rather than counselling. The client responded to the closeness and empathy provided so as to divulge delicate material and was encouraged to seek help elsewhere. If the dentist were not aware, the client could be harmed as cautioned by McLeod. ${ }^{41}$ But, if a counsellor were available in the practice, direct referral would be able to help the patient resolve their problem.

\section{The Egan Model}

This method provides a structure for counselling to follow. ${ }^{44}$ Aspects of dental treatment can be related to the Egan framework (Fig. 1). Using this approach, the counsellor can help the 'patient' to concentrate on areas of life presenting barriers to getting

\section{Fig. 1 Using the Egan model to facilitate dental treatment}

Stage I Part 1 The Story: Equates to History taking

Part 2 Blind spots: The presenting physical symptom may be a superficial symptom of something deeper (described by Broome as: 'one facet of the multifaceted unitary reality') Part 3 Leverage: Ways of overcoming blind spots, facing underlying problems

Stage II Part 1 Possibilities:Treatment must be suitable for the patient. The counsellor could ensure patients are psychologically able to accept treatment by focussing on unresolved problems causing barriers. Part 2 Change the Agenda: Is the patient keen to get the work done and prepared to consider changes in routine etc.

Part 3 Commitment: Does the patient return for more treatment - have they cleaned their teeth, are they ready for change? etc.

Stage III Part 1 Possible actions: Agreement between dentist and patient

Part 2 Best fit

Part3 Plan 


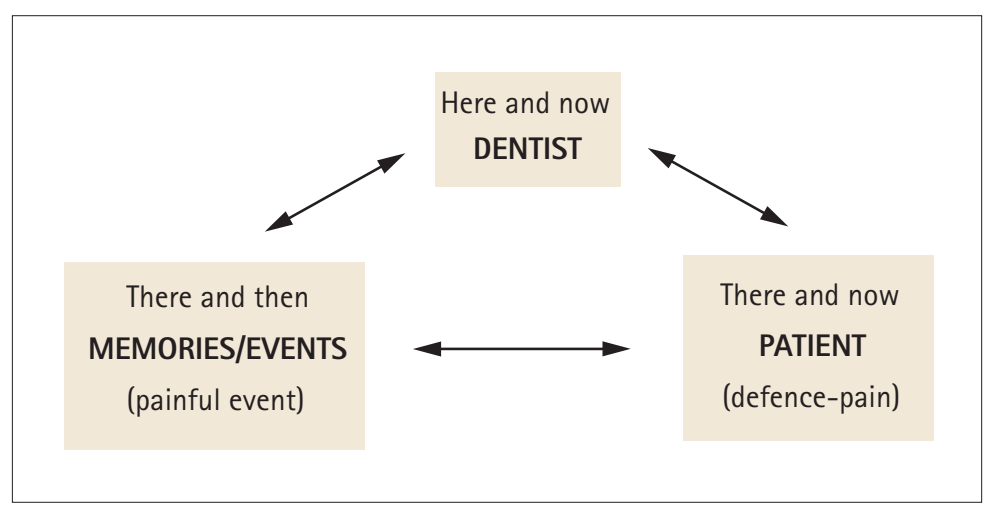

Fig. 2 Matan's Triangle demonstrates how the patient may transfer past events onto the dental experience

treatment undertaken (Clinical Case 4), or, the framework may be used to provide the required focus, allowing the patient to complete treatment where otherwise they might fail (Clinical Case 2).

\section{Psychodynamic}

Patients - particularly those who are nervous or phobic (Clinical Case 4) - may impose distorted past events or relationships onto the dentist in the form of transference. ${ }^{45}$ This usually involves regression (the psychological state as the patient moves from control to less well controlled); the dentist may be viewed as 'the caring parent' or 'the powerful and potentially harmful adult' - relating this back to unpleasant past experiences - abuse etc. ${ }^{46}$ If the dentist is unaware of this possibility he/she may act inappropriately. The counsellor attached to a dental team could educate the staff using Matan's Triangle to demonstrate the dynamics of this relationship (Fig. 2).

If the dentist understands the role of transference in this psychodynamic relationship, s/he will be able to adapt to the patient's needs, reformulating the way they relate to the patient allowing them to return from the childlike to the adult state and also be aware that they, as dentists, may themselves be using transference, subconsciously reacting to the patient. Where dentist and patient are unable to work together, the counsellor could help by exploring barriers to the formation of a satisfactory treatment alliance. ${ }^{47}$

\section{Cognitive behavioural therapy (CBT)}

Using the view of human experience involving the four interactive elements of cognition, emotion, behaviour and physiology, CBT helps clients break out of negative chains reactions (Fig. 3). ${ }^{48}$ By analysing behaviour and attitudes etc., the patient can be helped to change core beliefs and thereby achieve symptom reduction and behavioural change.

The role of this approach to the treatment of a patient has been described in

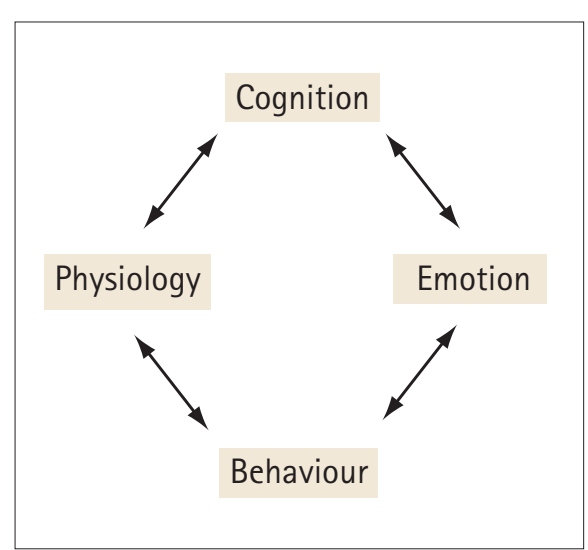

Fig. 3 The relationship of the elements involved in negative chain reactions (after Scott and Dryden 1998). ${ }^{43}$

Clinical Case 1. It is useful for neurotic or depressed individuals ${ }^{49}$ and also for patients who retch. Susan Wright (1980) ${ }^{32}$ compared 53 retchers with a group of controls and found no evidence that retchers were neurotic. She concluded that since retching is multifactorial in origin, low levels of neuroticism contribute to the condition. These patients could be helped using counselling to determine whether problems in their past make them react in this way and, by analysing their behaviour, help them to overcome their phobia. HoadReddick $^{50}$ used a relaxation technique developed by the National Childbirth Trust, ${ }^{51} 14$ patients out of a group of 19 were helped to wear dentures by making them reconsider their problem and then, through breathing instruction, break the retching habit by increasing their confidence. This type of treatment could involve the use of a person-centred approach by a counsellor to elicit the cause and a CBT approach to increase the patient's awareness and effect change.

\section{DISCUSSION}

The case has been made for the inclusion of a counsellor in the dental team. In general medicine, patients with somatic symptom presentations are common but are seriously under-diagnosed. ${ }^{30}$ The same applies to some aspects of dentistry partly because dental education has, until recently, been based in science and biology (body focussed) and has neglected psychology, sociology or spirituality. The clinician today needs to focus on both mind and body. Patients tend to view dentists as providing symptom relief but in some areas, for example, long-term headaches or atypical facial pain, if the patient could become aware - through counselling - of the opportunity for personal growth, the problem might be contained. Broom ${ }^{27}$ suggests that such conditions might respond to psychodynamic work using the G00D/BAD splitting where the 'patient' has a poor cohesive sense of self.

A new clinical panorama would recognise that the main visible manifestation of a disease is a physical dimension but would focus on non-physical, psychological, social and spiritual elements of the disease process. Patients who would benefit from this approach include those:

- Who are frightened or phobic

- Diagnosed as requiring long and complex treatment

- With cancerous or pre-cancerous conditions, (Clinical Case 5)

- Exhibiting behavioural habits affecting their teeth, muscles or joints

- Suffering from psychological problems eg depression preventing them from accepting treatment or whose condition is not yet being treated.

The difficulty of attempting to get this approach accepted in the profession is due to the lack of evidence as there has been little research into the role counselling can play in the care of patients. ${ }^{52}$ Increasingly in medicine there is a requirement for practice to be evidence based. ${ }^{53} \mathrm{CBT}$ is the area of counselling most suited to formal research with the possibility of controlled randomised trials versus placebos. There urgently needs to be research focussed on evidence-based practice in the use of counselling related to dentistry so that the approach described above is generally accepted.

\section{CONCLUSION}

This paper has attempted to describe ways in which counselling is relevant to dentistry. There are two strands. Firstly it is suggested that dentists should have a wider understanding of the dentist-patient relationship and an active awareness of the role counselling could play in their practices to allow provision of true holistic care. By having a better understanding of the dynamics of their relationships with patients and colleagues, practitioners would become more insightful and reflective and would be able to respond more 
effectively to patients' needs. This in turn would reduce stress on the dentist and make the working environment more fulfilling.

Secondly it has been demonstrated that a counsellor could benefit the whole dental team by advising and taking an active role in patient care and management. If such a counsellor had an understanding of integrated practice, they could proceed from Rogers Core Skills, through Egan, to psychodynamic or CBT as appropriate. In addition to seeing clients/patients on referral, the counsellor could help the team members to view patients as a whole and understand that:

'There are some things which cannot be learned and one of these is the meaning of a patients' illness. This must be discovered by the patient and the clinician working collaboratively'. ${ }^{27}$

If dentistry wishes to be viewed as a 'true profession' and a 'vocational training', it must look to wider horizons which will benefit patients as a whole - we must learn to listen to our patients.

'All of us have unseen capacities for development. Mutual respect means valuing unknown potentialities of the other as a separate, unique person' ${ }^{54}$

It seems certain that the practitioners who focused their practice in this way would have greater fulfilment in their work and thus would provide maximum benefit to their patients. If appropriate evidence-based research were conducted, the importance of this approach would be recognised.

1. Forrest W. Stresses and the self-destructive behaviour of dentists. Dent Clin North Am 1978:22: 316-371.

2. Cooper C L, Watts J, Kelly M. Job satisfaction, mental health and job stressors among general dental practitioners in the UK. Br Dent J 1987; 162: 77-81.

3. Blinkhorn A S. Stress and the dental team: a qualitative investigation of the causes of stress in general dental practice. Dent Update 1992; 19: 385-387.

4. Freeman R, Main J R R, Burke F J T. Occupational stress and dentistry: theory and practice. Part 1. Recognition. BrDent J 1995; 178: 214-217.
5. Newton J T, Baghaienaini F, Goodwin S R, Invest J, Hubbock M, Marouf S N. Stress in dental school: a survey of students. Dent Update 1994; 21: 162-164.

6. Heath J R, Macfarlane TV, Umar M S. Perceived sources of stress in dental students. Dent Update 1999; 26: 94-100.

7. Grandy TG, Westerman $\mathrm{GH}$, Combs $\mathrm{CE}$, Turner $\mathrm{CH}$. Perceptions of stress among third year dental students. J Dent Educ 1989; 53: 718-721.

8. Kerr N W. Dental pain and suffering prior to the advent of modern dentistry. Br Dent J 1998; 184: 397-399.

9. Proskauer C, Witt FH. Bildgeschichte der Zahnheilkunde, Verlag M.Du Mont Schauberg, Koln 1962.

10. Hugo V. 1806-1885. Les Miserables. Pub 1862.

11. Woodforde J. The strange story of false teeth. London: Routledge and Keegan Paul, EC4, 1968.

12. Anderson J N. The value of teeth. Br Dent J 1965; 119: 98-103.

13. Todd J E, Walker A M. Adult Dental Health Vol. 1. England and Wales 1968-78. London: HMSO, 1982.

14. Todd J E, Lader D. Adult Dental Health. 1988 United Kingdom. Office of population, censuses and surveys. London: HMSO, 1991.

15. Lufkin A W. A history of dentistry. London: Henry Kimpton, 1948.

16. Haines R W, Mohuiddin A. Handbook of Human Embryology. E \& S Edinburgh and London: Livingston Ltd, 1965, Fourth edn, 1968.

17. Moulton R E. Emotional factors in non-organic temporo-mandibular joint pain. Dent Clin NAmerica 1966; 609-619.

18. Freeman R. Barriers to accessing dental care: patient factors. Br Dent J 1999; 187: 141-144.

19. Argyle M. Social Interaction. London: Methuen, 1973.

20. Freud A. Selected writings. Chapter 6 . The role of bodily illness in the mental life of children (1952). London: Penguin Books, 1998.

21. Dolan TA, Berkley D B, Mulligan R, Saunders M J. Geriatric dental education and training in the United States: 1995 White Paper findings. Gerodontol 1996; 13: 94-109.

22. Shakespeare William. 1564-1616. As you like it Act II, Scene 7, first mentioned 1600, first published 1623

23. Smith S, Norton K. Counselling skills for Doctors. Buckinghamshire: Open University Press, 1999.

24. Allen J, Bor R. Counselling. In: A Baum (ed). Handbook of Psychology, Health of Medicine. Cambridge: Cambridge University Press 1997: 206-209.

25. Freeman R, Lamey P-J. Clinical and theoretica observations on Atypical Facial Pain. Psychoanal psychother 2000; 14: 23-26.

26. Freeman R E. Dental anxiety:A multifactorial aetiology. Br Dent J1985: 159: 406-408.

27 Broom B. Somatic illness and the patients other story. Free Assocn. Books, London 1997. Chapter 1. Seeing and not seeing. Chapter 4. Diagnosis and engaging the patient.

28. Moulton RE. Oral and dental manifestations of anxiety. Psychiatry 1955a; 18: 261-273.

29. Freeman $R$, Kells $B$. A dysmorphophobic reaction to cosmetic dentistry: observations and responses to psychotherapeutic intervention. Psychoanal psychother 1996; 10: 21-31.

30. Green CS, Olson R E, Laskin D M. Psychological factors in the aetiology, progression and treatment of MPD syndrome. J Am Dent Assoc 1982; 105: 443-448.
31. Feinmannn C, Harris M. Psychogenic facial pain. Part I The clinical presentation. Br Dent J 1984; 156: 165168. Part II. Management and prognosis. BrDent J 1984; 156: 205-208.

32 Wright S M. An examination of the personality of dental patients who complain of retching with dentures. BrDent J 1980; 148: 211-213.

33. Barsby M J. The use of hypnosis in the management of gagging and intolerance to dentures. Br Dent J 1994; 176: 99-102.

34. Clarke N G. Occlusion and myofacial pain dysfunction: is there a relationship? J Am Dent Assoc 1982; 104: 443-446.

35. Coulthard P, Morris S, Harrington A J. Unexplained physical symptoms in dental patients. Br DentJ 1998 . 184: 378-382.

36. Rogers $\mathrm{C}$. On becoming a person. London: Constable and $\mathrm{Co}, 1961$

37. Borghetti-Hiscock I. Exploratory ideas on the role of the psychotherapist in a heart-transplant team: thinking aloud. Psychoanal Psychother 2000; 15: 131-152.

38. Diamond J. Because cowards get cancer too.... London:Vermilion, Random house. 1998. Chapter 10 pp.192-193.

39. General Dental Council. The Undergraduate Dental Curriculum. The first five years. London: GDC, 1997.

40. Anon: Private versus NHS. Leading article. Br Dent $J$ 1998; 184: 365.

41. McLeod J. An introduction to counselling. Buckingham: Open University Press. Second edn. 1998.

42. Dryden W. Key issues for counselling in action. London: SAGE Publications, 1989.

43. Feltham C. What is Counselling? London: SAGE Publications, 1995.

44. Egan G. The skilled helper. A problem-management approach to helping. Pacific Grove: Brooks/Cole Publishing Co. USA. Sixth edn, 1998.

45. Freeman R. Communicating effectively: some practical suggestions. Br Dent J1999 : 187: 240-244.

46. Jacob S. Psychodynamic Counselling in action. London: SAGE Publications, 1988.

47. Greenson R R. The technique and practice of psychoanalysis. London: Hogarth Press, 1989.

48. Scott M J, Dryden W. The cognitive-behavioural paradigm. Chapter 7 in Handbook of Counselling psychology. Woolfe R, DrydenW (ed). London: Sage Pub. Ltd, 1996.

49. Fennel M J V. In:Hawton K, Salkovskis PM, Kirk J and Clark DM. (ed) Cognitive Behavioural Therapy for psychiatric problems: a practical guide. Chapter 6 Depression. Oxford: Oxford University Press, 1990

50. Hoad-Reddick G. Gagging: a chairside approach to control. BrDent J 1986; 161: 174-176.

51. National Childbirth Trust. Breathing control in labour. 1958, and Breathing in Labour 1958. London: National Childbirth Trust.

52. Milton M. Evidence-based practice: issues for psychotherapy. Psychoanal psychother 2002; 16: 160-172.

53. Ash M M. Paradigmatic shifts in occlusion and temporomandibular disorders. J Oral Rehab 2001; 28: $1-13$.

54. Hobson R F. Forms offeeling. The heart of psychotherapy. Tavistock, Routledge. 1985. Book III. Heart of darkness page 279 . 